Int. J. Electrochem. Sci., 15 (2020) 6938 - 6954

International Journal of

ELECTROCHEMICAL

SCIENCE

$\underline{\text { www.electrochemsci.org }}$

\title{
Preparation and Characterization of Polyamide6/Organic Clay Nanocomposite as protective coating for Carbon Steel
}

\author{
Layla A. Al Juhaiman*, Alanood A. Aljaghwani, Waffa K. Mekhamer \\ Chemistry Department, King Saud University, Riyadh, Saudi Arabia \\ *E-mail: ljuhiman@ksu.edu.sa
}

doi: $10.20964 / 2020.07 .79$

Received: 30 March 2019 / Accepted: 16 February 2020 / Published: 10 June 2020

\begin{abstract}
In this work Polyamide/organic clay nanocomposite (PCN) was successfully prepared. The raw clay was collected from Khulays area north of Jeddah in Saudi Arabia. After grinding, it was washed with water, thereafter it was saturated with $0.5 \mathrm{M} \mathrm{NaCl}$ solution to obtain the sodium clay $(\mathrm{NaC})$. To obtain the organoclay (OC), the $\mathrm{NaC}$ was modified with Cetylpyridinium chloride (CPC). Polyamide6/organoclay nanocomposites (PA6/OC NCs) were prepared at 1,2,3,4 and $5 \mathrm{wt} \%$ of OC. The PA6/OC nanocomposites were characterized using Fourier transform infrared spectroscopy (FTIR), X-ray Diffraction (XRD), Scanning electron microscope (SEM) as well as transmission electron microscope (TEM). The FT-IR spectra of OC show the appearance of new bands of the constituents of CPC which gives an evidence for the presence of the organic component $\mathrm{CPC}$ in the OC structure. The XRD results for OC showed a shift in $\mathrm{d}_{001}$ spacing from $10.93^{\circ} \mathrm{A}$ for $\mathrm{NaC}$ to $20.63^{\circ} \mathrm{A}$ for $\mathrm{OC}$. The XRD results for PA6/OC nanocomposites showed the loss of the clay crystalline structure at the low clay loading of 1-3 wt $\%$. From TEM results, the PA6/OC nanocomposites at 1,2 , and $3 \mathrm{wt} \%$ of OC showed exfoliated structures while the 4 and $5 \mathrm{wt} \%$ showed small portion of intercalated structure. The SEM results for the OC and PA6/OC showed a good homogeneous mixture in the PA6/OC nanocomposites. The anticorrosive properties of PA6/OC nanocomposites coatings on C-Steel were investigated using electrochemical impedance spectroscopy (EIS) and Potentiodynamic polarization in $3.5 \mathrm{wt} \% \mathrm{NaCl}$ electrolyte. Results showed that the PA6/OC nanocomposite coatings have better corrosion protection of C-Steel than pure PA6. The PA6/OC nanocomposite coatings containing $5 \mathrm{wt} \%$ of the OC exhibited the best corrosion protection which reached about $75 \%$.
\end{abstract}

Keywords: Polyamide6; Organic clay; Nanocomposite; XRD; EIS; Potentiodynamic polarization

\section{$\underline{\text { FULL TEXT }}$}

(C) 2020 The Authors. Published by ESG (www.electrochemsci.org). This article is an open access article distributed under the terms and conditions of the Creative Commons Attribution license (http://creativecommons.org/licenses/by/4.0/). 